\title{
ENSINO MEDIADO PELO COMPUTADOR: NOVOS PAPÉIS, NOVOS DESAFIOS PARA PROFESSORES DE LÍNGUAS ESTRANGEIRAS
}

\author{
Eliane Carolina de Oliveira*
}

\section{Resumo}

O presente trabalho discute a questão da inserção de recursos tecnológicos e de práticas de ensino mediado pelo computador (EMC) no ensino de línguas estrangeiras (LE). Para tanto, enfoca as eventuais mudanças nos papéis e funções dos profissionais de ensino de idiomas ao passar da cultura da sala de aula presencial para o ambiente virtual de aprendizagem de línguas, com relatos de professores de LE que vêm experienciando a inserção de novas tecnologias nos âmbitos da formação e atuação profissional serão apresentados. Para tal propósito, a unidade de análise utilizada foi um conjunto de mensagens eletrônicas trocadas pelos participantes de um curso on-line de pós-graduação cujo eixo central centrou-se na discussão de teorias de aquisição de L2/LE e na aprendizagem mediada pelo computador.

Palavras-chave: ensino de línguas estrangeiras, ensino mediado pelo computador, novos papéis.

\section{Computer-mediated learning: new roles, new challenges for foreign language} teachers

\section{Abstract}

This work is concerned with the insertion of technological resources and computer mediated educational practices in foreign language teaching. It focuses the eventual changes in the roles and functions of foreign language teaching professionals when moving from the culture of traditional to online classroom environment. Some reports from foreign language teachers who are experiencing the insertion of new technologies in their educational and professional contexts will be presented. The source of such reports are a set of electronic messages exchanged by the participants of a post-graduation on-line course whose central discussion themes were foreign language acquisition theories and computer mediated language learning (CALL).

KEY wORDS: computer mediated language teaching, foreign language teaching, new roles.

\section{INTRODUÇÃO}

Nas últimas décadas, temos assistido a profundas mudanças no campo da informação e do conhecimento proporcionadas pelo

* Professora de Língua Inglesa e Didática de Ensino de Inglês da Faculdade de Letras da UFG e doutoranda em Estudos Lingüísticos na UFMG. E-mail: ecaol@ig.com.br 


\section{Revista Solta a Voz, v. 16, n. 1}

progresso tecnológico e delas participado. As novas tecnologias de informação e comunicação (TICs) possibilitam não só mudanças diárias no cotidiano das pessoas e nas suas relações sociais, mas também delineiam novos espaços e fontes de aprendizagem no campo educacional.

Fora do espaço escolar, o conhecimento e a informação estão cada vez mais ao alcance dos estudantes por meio de outros recursos. A televisão a cabo, os cassetes, os cd-roms e a rede internet tornaramse fontes às quais os alunos podem ter acesso para obter conhecimento sobre as línguas estrangeiras (LE) (Gremmo, 1998). O desenvolvimento tecnológico proporciona, assim, uma nova dimensão ao processo educacional, uma dimensão que transcende os paradigmas ultrapassados do ensino tradicional.

Se as tecnologias fazem parte da vida do aluno fora da escola das mais diversas formas, elas também deveriam fazer parte da sua vida dentro da escola (Sampaio e Leite, 2000), a despeito de muitos profissionais, entretanto, não quererem aceitar as mudanças advindas delas. Resistir à utilização de novas tecnologias e continuar a sentir segurança na detenção do saber e no domínio da sala de aula é muito mais cômodo. Outros, com visão mais moderna, reconhecem que este pode ser um instrumento eficaz na educação.

Diante destes posicionamentos antagônicos, é importante salientar alguns questionamentos, como os seguintes: as pessoas que lidam com a educação em geral estão preparadas em termos informacionais para o advento do computador? Que mudanças advêm da introdução desse novo elemento para o paradigma educacional, especificamente para os papéis dos profissionais de ensino?

No decorrer do meu percurso profissional como educadora em diferentes níveis e contextos educacionais e, posteriormente, como formadora de futuros professores de LE, a questão do papel e da postura do profissional de ensino no meio presencial já se fazia presente nas minhas reflexões. A minha recente familiarização e decorrente integração de recursos computacionais no âmbito profissional (e também pessoal) acentuaram ainda mais a sempre atual preocupação com os papéis dos professores, sobre como eles adquirem conhecimentos e desenvolvem habilidades e competências para ensinar.

Sabe-se que, tradicionalmente, o meio presencial tem-se constituído no parâmetro para a formação inicial de professores e também 
Revista Solta a Voz, v. 16, n. 133

no contexto em que, posteriormente, eles irão atuar. A formação experienciada pela maioria dos profissionais de ensino é, não somente fundamentada no meio presencial, mas também orientada às peculiaridades desse ambiente. Se almejamos, portanto, a formação de docentes mais preparados para lidar com ferramentas utilizadas em ambientes virtuais de aprendizagem e, sobretudo, com a inserção de novas tecnologias para fins educativos, é necessária uma capacitação desses professores enquanto ainda discentes.

Como docente de língua inglesa e formadora de futuros professores de LE, tais questões permeiam minhas reflexões sobre a formação de professores pré e em serviço. Concordo com Souza (2000, p. 17), ao criticar a crença de que "a mera compra de computadores trará melhorias qualitativas ao ensino". A inserção pura e simples dos recursos tecnológicos e de práticas de ensino mediado pelo computador (EMC) nesse processo, sem discussões mais profundas das implicações que tal inserção trará, é preocupante e necessita de ponderação. Acredito que a adoção e a eventual utilização das novas tecnologias pelos docentes vão depender da capacidade destes de se emanciparem e de se desprenderem das crenças sobre ensino-aprendizagem de LE que fazem parte de sua formação.

Sob essa ótica, este trabalho focaliza uma das várias temáticas discutidas em um curso on-line de pós-graduação de uma universidade federal da região Sudeste do País no qual fui participante. Tal curso teve como eixo central a discussão de teorias de aquisição de segunda língua/língua estrangeira (L2/LE) e a aprendizagem mediada pelo computador. Assim, o objetivo é apresentar um levantamento teórico inicial sobre as demandas que os professores de LE vêm experienciando diante da inserção de novas tecnologias, em particular o computador e a internet, na sua formação e atuação profissional. Trata-se de estudo principiador e que poderá trazer contribuições para os profissionais que, assim como eu, acreditam no potencial dos docentes para lidar positivamente com a inserção de novas tecnologias no auxílio aos aprendizes no seu processo de aquisição da LE.

Além da parte teórica, o trabalho conta igualmente com a análise de um corpus coletado junto ao grupo de alunos participantes do curso de pós-graduação mencionado, com a qual tencionamos traçar paralelos a respeito do próprio EMC e das novas atribuições dos profissionais de ensino nesse ambiente. 


\section{Revista Solta a Voz, v. 16, n. 1}

\section{REFERENCIAL TEÓRICO}

$\mathrm{Na}$ literatura dessa área específica, tanto no âmbito nacional quanto internacional, encontram-se vários trabalhos que, de forma geral, salientam as necessidades desenvolvimentais dos educadores ao passar da cultura da sala de aula presencial para o ambiente virtual de aprendizagem de LE.

Johnson (2000), por exemplo, destaca que, embora os educadores já assumam papéis mais tradicionais como os de aprendizes, empreendedores e planejadores instrucionais, as novas ferramentas tecnológicas estão redimensionando os papéis de ambos os aprendizes e os educadores de forma inusitada.

Com a profusão de software e hardware disponíveis no mercado bem como os recursos encontrados na rede internet como portais educacionais, tutoriais, cursos pagos e gratuitos de desenvolvimento profissional, alguns inclusive com direito à titularidade, a autora citada afirma que os professores têm a oportunidade de direcionar sua própria aprendizagem e dar continuidade à sua formação, inclusive produzindo e divulgando os materiais que elaboram. Assim, gerar conhecimento é outra função que a tecnologia proporciona aos educadores que encontram na internet um canal para publicar seus próprios materiais instrucionais baseados na rede.

Ao discutir os papéis e competências de professores que irão atuar em contextos digitais, Queiroz e Mustaro (2003) apresentam um quadro, que contrasta o paradigma atual de ensino representado pelo contexto eletrônico.

Analisando tal quadro e contrastando-o com o cenário educacional no qual ainda nos encontramos, podemos afirmar que o paradigma proposto como ideal, para a nova dimensão que se apresenta, encontra-se ainda incipiente. Necessitamos transpor a visão tecnofóbica (Corrêa, 2003) ou compuphobia (Pilus, 1995) de total aversão ao uso das TICs por parte dos educadores que julgam que a máquina irá substituir o professor e, dessa forma, desumanizar a educação. Ao nos familiarizarmos com os recursos tecnológicos, constataremos que tal visão é infundada, que nossas práticas educativas cotidianas podem ser inovadas e que o desenvolvimento tecnológico pode proporcionar uma nova dimensão ao processo educacional como um todo. 
Revista Solta a Voz, v. 16, n. 135

QUADRO 1: Paradigma educacional atual $x$ paradigma emergente.

\begin{tabular}{|l|l|l|}
\hline Em relação à (ao) & Como é atualmente & Como deveria ser \\
\hline Professor & $\begin{array}{l}\text { Possui e transmite o co- } \\
\text { nhecimento. }\end{array}$ & Guia os estudos. \\
\hline Aluno & $\begin{array}{l}\text { Recebe os conhecimen- } \\
\text { tos passivamente. }\end{array}$ & $\begin{array}{l}\text { Interage com os conteú- } \\
\text { dos e os grupos e apren- } \\
\text { de de forma autônoma. }\end{array}$ \\
\hline Sala de aula & $\begin{array}{l}\text { Local de transmissão de } \\
\text { conhecimento. }\end{array}$ & $\begin{array}{l}\text { Local de construção e } \\
\text { troca de conhecimento. }\end{array}$ \\
\hline $\begin{array}{l}\text { Experiência } \\
\text { educacional }\end{array}$ & $\begin{array}{l}\text { Processo de transmissão } \\
\text { hierárquica do professor } \\
\text { para o aluno. }\end{array}$ & $\begin{array}{l}\text { Processo de troca entre os } \\
\text { membros do grupo que é } \\
\text { integrado pelo professor. }\end{array}$ \\
\hline $\begin{array}{l}\text { Aprendizado } \\
\text { e estudo }\end{array}$ & $\begin{array}{l}\text { Obrigatório, passível de de } \\
\text { punição. }\end{array}$ & $\begin{array}{l}\text { Agradável conduz ao } \\
\text { crescimento). }\end{array}$ \\
\hline Conteúdo curricular & $\begin{array}{l}\text { Preestabelecido e de for- } \\
\text { mato rígido e restrito. }\end{array}$ & $\begin{array}{l}\text { Flexível e de estrutura } \\
\text { aberta que pode dire- } \\
\text { cionar para múltiplos ca- } \\
\text { minhos. }\end{array}$ \\
\hline $\begin{array}{l}\text { Novas tecnologias } \\
\text { de comunicação }\end{array}$ & $\begin{array}{l}\text { Utilizadas somente para } \\
\text { chamar a atenção para um } \\
\text { certo tópico torná-lo, des- } \\
\text { sa forma, mais “interes- } \\
\text { sante”. }\end{array}$ & $\begin{array}{l}\text { Fazem parte do ambiente } \\
\text { espacial da sala de aula e } \\
\text { apresentam diferentes ti- } \\
\text { pos de mídia integrada e } \\
\text { simultânea. }\end{array}$ \\
\hline $\begin{array}{l}\text { Tecnologia e } \\
\text { informática } \\
\text { educacional }\end{array}$ & $\begin{array}{l}\text { O professor teme ser } \\
\text { substituído pela máquina } \\
\text { instrucional. } \\
\text { tecnologias de }\end{array}$ & $\begin{array}{l}\text { São utilizadas pelo pro- } \\
\text { fessor, que estrutura suas é vista como } \\
\text { aulas antecipadamente. } \\
\text { umação } \\
\text { da aprendizagem. }\end{array}$ \\
\hline $\begin{array}{l}\text { Tanto o professor quanto } \\
\text { os alunos as utilizam - o } \\
\text { que possibilita a troca de } \\
\text { conhecimento e idéias. }\end{array}$ \\
\hline
\end{tabular}

Adaptado de Queiroz e Mustaro (2003).

$\mathrm{Na}$ aprendizagem de língua mediada pelo computador (ou CALL, no termo original em inglês), Lévy (1997) nos lembra que o papel do professor irá variar dependendo da atuação do computador como tutor ou tool. Se o computador atua como tutor, ele será o professor substituto, aquele que, baseado nos fundamentos do behaviorismo, fornece ao aprendiz prática em exercícios do tipo repetição (drills) ou 


\section{Revista Solta a Voz, v. 16, n. 1}

lúdicos (games), e que provê o feedback apropriado. O computador como tool, ou ferramenta instrucional, por sua vez, não possui a natureza avaliativa do papel de tutor. Ao contrário do primeiro, o professor é o elemento-chave que irá preparar o aluno para utilizar de forma eficaz os recursos computacionais, auxiliando e orientando o aprendiz em busca de um papel mais autônomo.

Assim observamos que novas exigências se impõem aos professores que, além da formação lingüística e acadêmica em geral, necessitam também de formação em tecnologia e em ambientes informatizados de ensino para atuar. Em outras palavras, de alfabetização tecnológica.

Sampaio e Leite (2000, p. 75) definem a alfabetização tecnológica do professor como

um conceito que envolve o domínio contínuo e crescente das tecnologias que estão na escola e na sociedade, mediante o relacionamento crítico com elas. Este domínio se traduz em uma percepção global do papel das tecnologias na organização do mundo atual e na capacidade do professor em lidar com as diversas tecnologias, interpretando sua linguagem e criando novas formas de expressão, além de distinguir como, quando e por que são importantes e devem ser utilizadas no processo educativo.

Nessa capacitação dos docentes para ensinar por meio das novas mídias, exige-se que os professores desenvolvam o que Warschauer (2002) chama de electronic literacies, termo que particulariza algumas das idéias presentes na definição de Sampaio e Leite (2000).

Para o autor, electronic literacies envolve quatro tipos de letramento: computer literacy - relativo à familiaridade do usuário com o teclado e o computador de modo geral; information literacy - habilidade de localizar e analisar de maneira crítica material on-line; multimedia literacy - habilidade de produzir e interpretar materiais que contenham imagens, sons e textos; e computer-mediated communication literacy - conhecimento pragmático das interações on-line tanto de indivíduos quanto de grupos.

A alfabetização tecnológica pressupõe igualmente um componente que trate das funções e papéis do instrutor/facilitador on-line. O artigo de Berge (1995) lista os papéis e as funções do educador on-line ao mediar a comunicação via computador. O autor declara que há várias condições para a tutoria on-line durante o planejamento e 
Revista Solta a Voz, v. 16, n. 137

implementação tanto dos materiais quanto do curso e agrupa-as em quatro áreas: pedagógica, social, gerencial e técnica.

A primeira diz respeito às tarefas do instrutor como um facilitador da aprendizagem on-line. A segunda está relacionada à criação de um ambiente amigável que promova as relações interpessoais de forma a tornar o grupo coeso e mantê-lo como tal. A área gerencial, por sua vez, envolve questões de natureza mais administrativa, mais organizacional como, por exemplo, determinar os objetivos do curso, os horários, regras e normas a serem seguidas, além do próprio gerenciamento das interações. Na última área são agrupadas as recomendações técnicas que possibilitarão aos aprendizes concentrarem-se nas atividades e não no sistema e nas ferramentas do ensino on-line. Berge (1995) destaca ainda que, nesse recente ambiente educacional, ambos, os professores e os alunos, experienciarão novos papéis, funções e atividades os quais demandam tempo para seu desenvolvimento e uso efetivo.

As quatro áreas de funções do instrutor on-line propostas por Berge (1995) são retomadas no livro de Pallof e Pratt (1999) sobre comunidades virtuais de aprendizagem. O diferencial do trabalho desses autores reside no fato de não apresentar listas ou modelos de atuação, e sim discutir a importância de tais categorias comentando-as e exemplificando-as com base nas suas experiências práticas de condução de seminários on-line e na construção de comunidades virtuais de aprendizagem.

Apesar de se constituir em um importante aspecto na temática ora discutida e de oferecer subsídios para o preparo do professor de LE, defendo que somente a prescrição de funções, papéis e modelos ideais não é suficiente para uma mudança de atitude e, eventualmente, das práticas educativas por parte dos educadores.

Ramos e Freire (2003, p. 7) enfatizam que "a passagem do contexto presencial para o virtual pode causar repercussões de várias naturezas", dentre elas as de ordem psicológica reportadas por Mattos (2003). Preocupados com a formação docente, Ramos e Freire (2003) pontuam que, preparados, até então, para o meio presencial, os docentes que passam a atuar em uma ambientação virtual se deparam com modalidades de interação totalmente inusitadas, com novas mídias e linguagens, com novos recursos instrucionais. De acordo com as autoras citadas, tais questões, inéditas para muitos, em alguma medida os 


\section{Revista Solta a Voz, v. 16, n. 1}

reportam à (re)construção de sua identidade, dos papéis que desempenham e de sua atuação didático-pedagógica.

Diante do exposto, considero essencial uma educação que leve o professor em formação a, por um lado, refletir sobre seu próprio processo de aquisição da LE, sobre como as novas TICs podem auxiliálo nesse processo, mas também, por outro lado, obter experiências empíricas no próprio ambiente de formação que o levam a participar ativamente da construção do próprio conhecimento.

Concordamos com Sampaio e Leite (2000) quando ressaltam a necessidade de se criarem condições para que os futuros professores não só tomem conhecimento sobre novas formas de aprendizagem e interação entre as pessoas proporcionadas pelo computador, mas que também experienciem e reflitam sobre as possibilidade de uso dessa ferramenta no processo de ensino-aprendizagem. Estaríamos, dessa forma, possibilitando uma formação não somente fundamentada no meio eletrônico, mas também orientada às peculiaridades desse ambiente.

Como mencionado na parte introdutória deste trabalho, apresentamos em seguida dados oriundos de uma lista de discussão na qual um grupo de alunos discutiu a temática da aprendizagem mediada pelo computador e teorias de aquisição de LE. Nosso objetivo foi averiguar as impressões expressas pelos participantes em relação aos papéis dos educadores diante da inserção das novas TICs no âmbito de ensino de LE.

\section{Discussão dos DADOS}

Nossa análise focalizou, primordialmente, os relatos enviados no decorrer do curso cuja natureza viesse ao encontro do tema tratado. Os comentários foram agrupados em duas partes:

1. visão dos participantes sobre CALL;

2. visão dos participantes sobre o papel do professor no ambiente de CALL.

O grupo contou com a participação inicial de vinte e nove alunos matriculados em categorias distintas: alunos efetivos (mestrandos e doutorandos) e alunos de disciplina isolada ou eletiva formando, segundo caracterização do professor, "um grupo plural e que conta com pessoas com alguma experiência com a presença da informática em situações de ensino e aprendizagem". Por razões diversas, o número final de alunos 
foi de quinze, tendo gerado até o último dia do curso um montante de 1.369 mensagens. É ainda importante mencionar que também os relatos daqueles que vieram a desistir do curso foram considerados, haja vista o teor dos comentários, que nos interessava. Para preservar a identidade dos participantes, tomamos o cuidado de abreviar os respectivos nomes.

\section{VISÃo dOS PARTICIPANTES SOBRE CALL}

Foi observada uma recorrência bastante grande nas opiniões dos cursistas, corroborando a parte teórica sobre a importância dos recursos computacionais na área educacional de modo geral e, especificamente, na aprendizagem de segundas línguas e/ou línguas estrangeiras como atestam os comentários a seguir:

[1]

[...] um ambiente rico para a troca de experiencias e idéias entre estudantes, profissionais e pesquisadores de várias áreas tanto no contexto nacional quanto estrangeiro. (E. C.,19 abr. 2004, 14:32 b)

[2]

Eu, como interessado nas questões de $S L A$, já havia observado o potencial dos recursos multimeios, internet e computadores de uma maneira geral em $S L A$, mas nunca bavia refletido e discutido como fizemos ao longo do curso. [...] Fiquei fascinado com a possibilidade de interagir (via texto, voz e vídeo) com pessoas de diferentes nacionalidades, nos diferentes cantos do mundo e falantes de idiomas os mais diversos. Também fiquei "viciado" em ler jornais on-line na internet. $O$ insumo em LE que podemos ter acesso é estrondoso. Bom, falo tudo isto sobre usar o computador de maneira informal (livre, leve e solto), por puro prazer.

(F., 15 jul. 2004, 15:27 h)

[3]

Hoje, mais do que nunca, não podemos negar que os PC'spodem (e são) ferramentas construtivas na elaboração, desenvolvimento e articulação do potencial comunicativo de um indivíduo. Isso é tão verdade que hoje criancas que, mesmo sem freqüentar cursos livres de inglês, ou ainda sem serem explicitamente expostas ao inglês em seu cotidiano, adquirem pequenas noçös gramaticais e imenso range vocabular apenas ao interagivem com seus games e chats de comunicação na rede. Creio, sim, que os PC's podem ser grandes ferramentas e acredito, também, que estas inquietaçōes dirigem os possiveis questionamentos relacionados ao CALL.

(A. C., 26 mar. 2004, 9:28 b) 


\section{Revista Solta a Voz, v. 16, n. 1}

Os participantes lembram igualmente que outros recursos eletrônicos já suscitaram reações negativas por parte dos docentes, inclusive comentaram a respeito da questão do receio de que o computador viesse a tomar o lugar do professor, a tecnofobia ou "compuphobia", mencionado por Corrêa (2003) e Pilus (1995). No grupo, esse temor não tem fundamento, pois os membros acreditam que o papel do professor extrapola os limites alcançados pela máquina. Como expresso pelo participante V., por sua natureza, o computador não possui dimensões sociais, afetivas e cognitivas do ser humano.

[4]

Penso que o computador não pode substituir o professor. Há duas passagens de Lessa que gosto muito e que ilustram muito bem esta idéia: "O computador é um artefato cultural como o livro, o rádio e a televisão e, por isso, só pode ser comparado a outro artefato cultural". Ou seja, não há porque comparar o computador com o professor. A outra citação seria: "O computador não substitui o professor, mas substitui com vantagem a folha de papel". Acho que estas passagens resumem tudo em que acredito. Não tenho o menor receio de ser substituida pelo computador. Meu papel como professora e educadora vai muito além do que uma máquina pode oferecer, a comecar pelo conhecimento das individualidades e características afetivas e cognitivas de meus alunos. (V., 19 abr. 2004, 9:54h)

Os participantes discutem ainda a questão da normalização (Bax, 2003) dos recursos eletrônicos na área educacional. Para muitos cursistas, assim como ocorreu com outros artefatos tecnológicos como a TV, o aparelho de som e o vídeo, os computadores também estarão inclusos nas práticas instrucionais de CALL dos professores. Os comentários a seguir ilustram tais opiniões:

[5]

Hoje, ao pensarmos no ensino de LE, nãopensamos em áudio e vídeo em separado; tais tecnologias já estão totalmente incorporadas às práticas de ensino-aprendizagem, $e$ contribuem para elevar o nivel de "comunicação" e "auntenticidade" das tarefas. (F. G., 27 mar. 2004, 7b)

[6]

No entanto, compreendendo como Bax que os computadores estarão totalmente integrados quando forem utilizados por professores e alunos como parte integrante das lições, mas como um recurso auxiliar, acredito que os computadores não precisam estar necessariamente em cada sala de aula para que seu uso esteja normalizado. Essa 
Revista Solta a Voz, v. 16, n. 141

normalização não implica a sua utilização em todas as aulas ou a sua presença na sala de aula. Os equipamentos de áudio, por exemplo, já estão totalmente integrados às aulas de linguas estrangeiras, mas isso não significa que eles estejam presentes em todas as salas de aulas ou em todos os momentos de um curso. Eles podem sim estar na sala de aula, mas podem ser levados para a sala somente quando necessários ou, ainda, ficar em uma outra sala. Ao meu ver, a normalização das práticas de CALL não passam NECESS ARIAMENTE pela disponibilização de computadores em todas as salas de aula, embora isso possa ser até desejável (mas financeiramente inviável no momento). (A. C., 29 mar. 2004, 13:49h)

É importante pontuar o debate dos participantes a respeito da questão das iniciativas de investimento nos recursos materiais e humanos para a utilização das novas TIC como as expressas nos relatos de 7 a 10. Observamos que os membros do grupo corroboram as assertivas que emitimos no decorrer do trabalho sobre a necessidade da capacitação docente para atuar nesta emergente esfera pedagógica.

[7]

O medo de inovar ainda é grande e muitas tentativas precisam ser feitas e testadas, como por exemplo, no espaço da formação de professores, para que se comece a vislumbrar um futuro em que se faça um uso adequado da tecnologia.

(A. L., 30 mar. 2004, 16:17b)

[8]

Para completar, volto a pensar que a proposta de Bax para o futuro de CALL, de normalização, deve começar pelos professores de línguas. Se não entendem como vivenciar CALL em seu processo de formação, seus preconceitos e suas crenças a respeito de uso de computadores continuarão no campo do senso comum, com poucos progressos na área. Não é o nosso caso...

(A. L., 1 abr. 2004, 9:52b)

[9]

Logo, a questão da capacitação de docentes para que haja mais CALL e EaD, bem como mais laboratórios de informática nas escolas é uma questão de tempo e preparação para isso. Acredito que a capacitação/ reflexão na área é básica e esse caminho já se iniciou tanto nas escolas, bem como nas Universidades/Faculdades.

(M., 4 abr. 2004, 10:15b)

[10]

Continuando, não é todo docente ou aprendiz que faz a transição e se adapta facilmente a tais mudanças como já foi discutido no curso. É de suma importância, 
42 Revista Solta a Voz, v. 16, n. 1

portanto, o preparo de ambos para a construção e gestão dos cursos on-line (no caso do professor) e para a participação (no caso do aluno).

(E. C., 20 abr. 2004, 9:45 h)

Houve, é claro, participantes que mencionaram o esforço despendido na participação (como alunos e professores) em atividades mediadas pelos recursos eletrônicos, mencionando aspectos particularmente delicados na interação virtual. Eles declaram que, embora o empenho tenha sido grande, as recompensas foram igualmente enormes. Os depoimentos de R., C., V. e V. S. confirmam isso:

[11]

[...] Apesar do enorme trabalho, vale muito a pena.

(R., 21 mar. 2004, 22:59h)

[12]

Precisa ter dedicação e disciplina! Entretanto, aprendi muito nesse processo.

(C., 5 jul. 2004, 13:46h)

[13]

Bem, é muito importante que o aprendiz se sinta à vontade no ambiente on-line. Nas primeiras conexões o que me deixava pouco à vontade e ansiosa era o vocabulário utilizado por alguns colegas. [...] a linguagem não se assemelhava à de uma sala de aula, e, sendo este o primeiro contato com uma disciplina on-line, isto assustava um pouco. [...] O próprio professor R. consegue balancear a linguagem teórica com uma menos formal. A motivação vem do conforto acima mencionado e do feedback dos colegas e do professor.

(V., 20 abr. 2004, 6:12b)

[14]

No que concerne à primeira [incursão no ensino a distância] foi uma experiência excelente, embora estivesse um tanto reticente no comeco. Senti falta da sala de aula tradicional (questão cultural), mas aos poucos fui desvencilhando de minhas inseguranças e percebendo o quanto essa modalidade assincrona de ensino (e-mail) havia me sedurido. Os resultados superaram minhas expectativas e contribuiram em muito para a minha decisão em continuar investindo em meus estudos (leituras pesquisas, etc.) nessa área.

(V.S., 15 jul. 2004, 20:46h)

Os depoimentos selecionados e a nossa própria participação no curso nos possibilitam inferir que, de forma geral, os participantes tor- 
Revista Solta a Voz, v. 16, n. 143

naram-se mais reflexivos sobre o ensino mediado pelo computador. Nossas visões foram ampliadas e nos sentimos impulsionados a buscar compreender melhor a contínua evolução das práticas instrucionais e a necessidade de assumir novos papéis e funções no nosso fazer pedagógico. Abordamos, assim, as percepções sobre as novas atribuições do professor que se fazem necessárias no âmbito do EMC.

\section{VISÃO DOS PARTICIPANTES SOBRE O PAPEL DO PROFESSOR NO AMBIENTE DE CALL}

Em relação aos papéis e funções do professor no ambiente midiatizado, os dados revelam que os participantes estão cientes da necessidade de mudança. Alguns mencionaram funções tradicionais como do professor que planeja, que propõe objetivos, do seu papel de gerenciador de tarefas e avaliador da aprendizagem além, é claro, do papel de motivador. Tais funções e papéis se estendem igualmente ao ambiente de ensino mediado pelos recursos tecnológicos. Os comentários 15 e 16 mostram esses pontos de vista.

[15]

O papel do professor, então, é fundamental. Tem que se ter um planejamento pedagógico, com objetivos a serem alcançados, dar uma tarefa especiffica (como a $A$. menciona) com critérios claros e fazer uma checagem depois com os alunos, verificando o que eles aprenderam depois da interação. Até uma conversa com os alunos sobre suas perceppóes sobre a atividade seria muito rico para o processo de ensino/ aprendizagem.

(C., 22 abr. 2004, 14:22h)

[16]

Também acho que o professor exerce um papel fundamental de motivador, ou mantenedor, talvez, do grau de motivação de seus alunos, independentemente do tipo de motivação do aluno, conforme Ellis aborda em seu texto. Já que não temos certeza se a motivação é causa ou resultado do sucesso na aprendizagem de uma língua estrangeira, devemos ter em mente que somos responsáveis por parte deste sucesso, mesmo que não possamos avaliar com acuidade as diferenças individuais de nossos alunos.

(Ed., 12 abr. 2004, 17:13b)

Grande parte dos comentários voltado para uma das características atribuídas ao EMC diz respeito ao envolvimento mais do apren- 
44 Revista Solta a Voz, v. 16, n. 1

diz no seu próprio processo de aprendizagem, ou seja, à questão da autonomia.

[17]

Realmente tanto os papéis do professor e do aluno mudam no ambiente virtual. Como já foi falado, o aluno precisa ser mais agente da sua aprendizagem (mais autônomo), o papel do professor é menos dominante. As crenças envolvidas nesse tipo de aprendizagem certamente vão influenciar o processo, portanto, seria muito importante que investigações nesse sentido fossem feitas. O professor e aluno, também, podem ser reflexivos nesse contexto.

(C., 29 abr. 2004, 18:27b)

[18]

[...] mais importante que ensinar apenas o idioma é ajudar os alunos a desenvolver estratégias metacognitivas, fornecendo a eles, assim, mecanismos de se tornarem responsáveis pelo próprio processo de aprendizagem dentro e fora da sala de aula, sujeitos engajados e envolvidos no processo, dispostos a buscar oportunidades de utilizar a segunda lingua. Eu acredito muito nisso. Se formos capazes de motivar nossos alunos desta forma, já será um grande feito.

(F. G., 23 mar. 2004, 23:25 h)

[19]

Em ambos, o professor, como mediador/facilitador, tem seu papel, já que desenvolver uma aprendizagem mais autônoma não significa deixar o aluno livre para desenvolver aquilo que quer, quando quer e do jeito que quer, mas propiciar condiços para que o complexo processo de ensinar-aprender língua estrangeira mediado pelo computador passe de dependente para mais independente, a fim de o aprendiz ter condições de chegar a um estágio mais autônomo de aprendizagem. Nesse caso, justifica usar Bax (2003, p. 26), na argumentação de que "that computers alone are insuficient".

(M., 1 abr. 2004, 19:48h)

A respeito da formação, da necessidade das "electronic literacies" (Warschauer, 2002), observei que grande parte dos participantes buscava de maneira autônoma ampliar seus conhecimentos sobre a informática educativa, porém, às vezes, tal capacitação era efetuada pela participação de um parceiro já experiente no uso dos recursos informatizados como nos demonstra A. C.

[20]

Em 2000, fui convidado a participar de um projeto de educação a distância que oferecia cursos de extensão on-line. Não tinha experiência nessa área, mas a 
Revista Solta a Voz, v. 16, n. 145

coordenadora do projeto estava concluindo um mestrado em tecnologia educacional e estava envolvida com essa questão havia bastante tempo.

(A. C., 13 jul. 2004, 17:58h)

[21]

Fui aluno de graduação do professor R. na UFSJ e a partir de algumas conversas que lá tivemos e da participação em um minicurso ("Introduction to CALL"), ministrado pelo professor, cresceu meu interesse por esta modalidade de ensino de Linguas Estrangeiras (com foco no Inglês). Além do minicurso, também tive a oportunidade de cursar no último periodo do curso de Letras uma disciplina on-line intitulada Inglês para Fins Empresariais, que me instigou a um aprofundamento em CALL. (L. G., 29 mar. 2004, 21:05 h)

No comentário 21, observamos que o interesse foi instigado pelo contato e pelas experiências do participante ainda durante a graduação, o que nos remete a nossa afirmação de que os estudantes devem obter experiências empíricas no próprio ambiente de formação que os levem a participar ativamente da construção do próprio conhecimento.

Um dado interessante e bastante debatido no decorrer do curso foi a questão das crenças sobre ensino e aprendizagem de LE em geral e, especificamente, em relação ao EMC. Os participantes demonstraram, pelos menos em suas práticas discursivas, estarem cientes de que tais pressuposições necessitam ser revistas em virtude do ensino emergente que se configura para o nosso futuro profissional. É pertinente mencionar ainda que o curso possibilitou a reflexão sobre as idéias anteriores sobre o tema e, conseqüentemente, uma reconstrução das crenças. Os comentários a seguir exprimem tais idéias:

[22]

Foi apenas um comentário sobre a sua reflexão. Concordo com o que vc dir. A minha reflexão é em direção a CALL/EAD. Durante muito tempo estivemos ancorados em nossas crenças (corretas ou não) e nas teorias desenvolvidas ao longo de nossa bistória para explicar os fenômenos sociais e psicológicos (cognitivos) subjacentes ao ensinol aprendizagem de linguas. Temos agora uma nova realidade emergida pelas possibilidade de aprendizagem de linguas mediadas pelas novas tecnologias, com as quais ainda não sabemos lidar, em decorrência de seus aspectos relacionados com o novo, o diferente. É natural que isso nos cause uma sensação de estranhamento, de desconforto e de insegurança. É um momento histórico para nós (um privilégio eu diria), já que esse processo se apresenta irreversivel e bastante promissor. O que quero dizer é que nossas crenças e 
46 Revista Solta a Voz, v. 16, n. 1

concepcões teóricas estão abaladas, pois além de termos que lidar com elas quando no contexto presencial, temos também que conviver com novas crenças e, infelizmente, com a falta de construtos teóricos próprios desse meio como sugere Warschauer. Mas não tenho dívidas de que é assim mesmo. O grande desafio está na nossa capacidade de movência entre uma modalidade e a outra, além da consciência de que são formas e meios diferentes, com características próprias mas que, no fundo, ambas têm a mesma finalidade: que os alunos aprendam lingua(s) estrangeira(s).

(V.S., 3 maio 2004, 13:29 b)

[23]

Realmente, acredito que nossas crenças estão intimamente ligadas com nossas experiências e o meio em que vivemos. E isto é extremamente relevante para refletirmos que somos responsáveis por uma grande parte das experiências de aprendizagem de nossos alunos. Ou seja, temos participação na formação das crenças de nossos alunos e, por isso, devemos sempre refletir que tipo de aprendiz queremos formar.

(V., 3 maio 2004, 9:11h)

\section{ConsideraçôES FINAIS}

O presente trabalho não abrange toda a gama de tópicos relacionados às teorias de aquisição de L2/LE e às práticas de CALL discutidas no curso mencionado na parte introdutória e nem esgota todos os possíveis direcionamentos que o tema suscita. Em todas as considerações aqui apresentadas, fica evidente a necessidade de se tomar como objeto de estudos mais aprofundados a atuação dos docentes no que concerne à inserção dessa nova modalidade de prática educacional mediada pelas novas tecnologias no processo de aprendizagem de L2/LE.

Pode-se perceber que as transformações tecnológicas que ocorrem de forma acelerada exigem das pessoas novas aprendizagens, novos perfis e o desenvolvimento de novas competências, gerando, assim, enormes desafios para a educação. O desenvolvimento de diferentes competências tornar-se-á possível por meio do processo de (re)construção de conhecimentos de ambos, professores e alunos, de seus papéis e de suas funções.

Tudo isso representa um desafio na área de formação de professores de LE. Sobrepujar os temores, os obstáculos e os conflitos e tomá-los como desafios irão certamente contribuir para a melhoria do sistema educacional em todos os níveis de ensino e, eventualmente, atingir um novo patamar de conhecimento. 
Revista Solta a Voz, v. 16, n. 147

\section{REFERÊNCIAS}

BAX, S. CALL. Past, present and future. System, v. 31, p. 13-28, 2003.

BERGE, Z. L. The role of the on-line Instructor/Facilitator. 1995. Disponível em: < http://jan.ucc.nau.edu/ mpc3/moderate/teach online.html $>$ ou $<$ http://www.emoderators.com/moderators/teach online.html $>$ Acesso em: 16 set. 2003.

CORRÊEA, J. Novas tecnologias da informação e da comunicação: novas estratégias de ensino/aprendizagem. In: COSCARELLI, C. V. Novas tecnologias, novos textos, novas formas de pensar. 2. ed.: Belo Horizonte: Autêntica, 2003. p. 43-50.

GREMMO, M. Learner autonomy: defining a new pedagogical relationship. Forum for Modern Languages Studies, v. 39, n. 2, 1998.

JOHNSON, M. Thinking about the future. Electronic School, v. 47, p. 1623, 2000. Disponível em < http://www.electronic-school.com/2000/ 01/0100flpart1.html > Acesso em: 12 jul. 2004.

LÉVY, M. Computer assisted language learning: context and conceptualization. Oxford: Oxford University Press, 1997.

MATTOS, A. M. A. Virtual classrooms in Brazil: teachers' difficulties and anxieties towards technology in language learning. Revista Brasileira de Lingüistica Aplicada, v. 3, n. 2, p. 115-132, 2003.

PALLOF, R. M.; PRATT, K. Construindo comunidades de aprendiragem no Ciberespaço: estratégias eficientes para salas de aula on-line. Porto Alegre, RS: Artmed, 1999.

PILUS, Z. Teachers' Interest in CALL and their level of computer literacy: some implications. ON-CALL, v. 9, 1995. Disponível em < http://www.cltr.uq.au/pncall/pilus93.html> Acesso em: 12 jul. 2004.

QUEIROZ, V.; MUSTARO, P. N. Roles and competencies of on-line teachers. The Internet TESL Journal, v. 9, n. 7, 2003. Disponível em: $<$ http://itesli.org/Articles/Queiroz-Online'Teachers.html $>$ Acesso em: 20 nov. 2003.

RAMOS, R. de C. G.; FREIRE, M. M. Do presencial para o virtual: um desafio para o professor de inglês. Disponível em: < http://www. 
48 Revista Solta a Voz, v. 16, n. 1

abed.org.br/antiga/htdocs/paper visem/rosinda de castro.htm> Acesso em: 16 set. 2003.

SAMPAIO, M. N.; LEITE, L. S. Alfabetização tecnológica do professor. Petrópolis, RJ: Vozes, 2000.

SOUZA, S. A. F. Internet e ensino de línguas. In: LEFFA, V. J. CD TELA (Textos em Lingüistica Aplicada). Publicação Eletrônica de Linguagem e Ensino, Curso de Mestrado em Letras, Universidade Federal de Pelotas, 2000.

WASCHAUER, M. A developmental perspective on technology in language education. Tesol Quarterly, v. 36, n. 3, p. 453-475, 2002.

Recebido em: 28 jan. 2005

Aceito em: 10 maio 2005 